\title{
NOVEL USE OF SUPERFICIAL CERVICAL PLEXUS BLOCK AND PECS I BLOCK FOR VAGAL NERVE STIMULATOR IMPLANT SURGERY IN A PAEDIATRIC PATIENT - A CASE REPORT
}

M. Long ${ }^{1}$, T.Y.S. Tan ${ }^{1}$

${ }^{1}$ KK Women's and Children's Hospital, Department of Paediatric Anaesthesia, Singapore.

\section{INTRODUCTION}

PECS block was first described as an alternative to thoracic epidural and paravertebral blocks in managing pain after breast surgery ${ }^{1}$. Since then, there have been modifications such as the PECS II block and expansion of its uses to include analgesia for Port-a-Cath insertion and removal ${ }^{2}$, minimally invasive cardiac surgery ${ }^{3}$ and CRT device implantation ${ }^{4}$. Superficial cervical plexus blocks have been described to be effective for analgesia preceding procedures in the head and neck region. These procedures include carotid endarterectomy, thyroidectomy, and even part of a combination of peripheral nerve blocks for shoulder surgery ${ }^{5}$.

A vagal nerve stimulator implantation surgery will involve incisions at both the lateral neck and pectoral region (Figures $1 \mathrm{~A}$ and $1 \mathrm{~B})$. As such, we postulate that a combination of the superficial cervical plexus block and PECS 1 block will be effective in managing post operative pain for a vagal nerve stimulator implant.

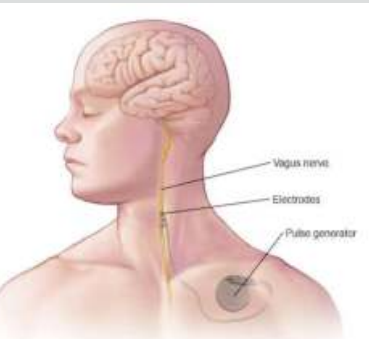

Figure 1A:

Vagal nerve stimulator implant location

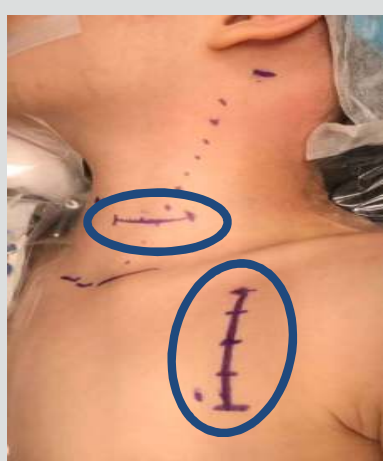

Figure 1B:

Blue ovals indicate incision sites

\section{CASE SUMMARY}

A 5 year-old girl, $17.5 \mathrm{~kg}$ with a history of refractory infantile epilepsy, presented for an elective vagal nerve stimulator implant surgery. Despite being on multiple anti-epileptic drugs, she had up to 20 episodes of seizures per day. She is non-verbal and communicates discomfort by pointing or making incomprehensible noises.

Patient was induced with IV Propofol 60mg, Fentanyl 30mcg and Atracurium $8 \mathrm{mg}$. She was intubated with a size 5 cuffed endotracheal tube using a McGRATH ${ }^{\mathrm{TM}}$ video-laryngoscope. A $22 \mathrm{G}$ intra-arterial cannula was inserted for haemodynamic monitoring.

After intubation, the left superficial cervical plexus block (Figure 2A) and PECS I block (Figure 2B) were performed aseptically using an in-plane approach with a Pajunk $50 \mathrm{~mm}$ needle under ultrasound (Sonosite, M-Turbo) guidance. Levobupivacaine $0.25 \%$ $2 \mathrm{mls}$ and $8 \mathrm{mls}$ were given respectively for the superficial cervical plexus and PECS I block after negative aspiration for blood.

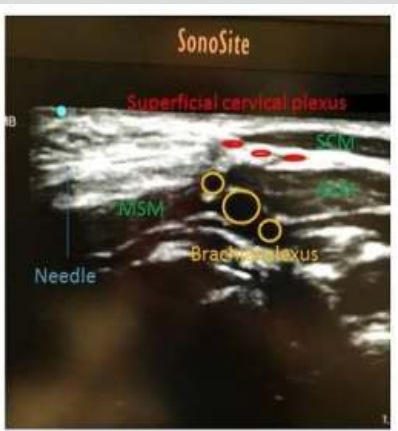

Figure 2A:

Left Superficial Cervical

Plexus Block

SCM: Sternocleidomastoid

ASM: Anterior Scalene Muscle

MSM: Middle Scalene Muscle

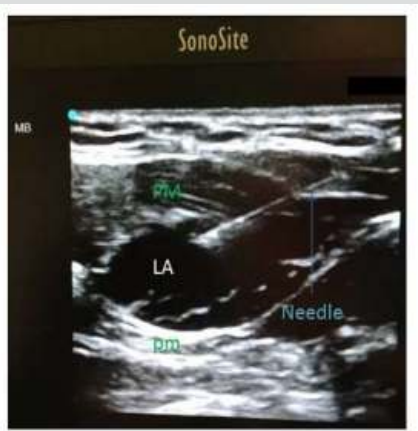

Figure 2B:

Left PECS I Block

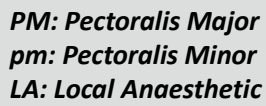

PM: Pectoralis Major

LA: Local Anaesthetic
Figure $1 A$ reproduced with permission from MCHS. Figures $1 B, 2 A$ and $2 B$ reproduced with parental consent

At the conclusion of an uneventful surgery, neuromuscular blockade was reversed with Atropine $0.3 \mathrm{mg}$ and Neostigmine $0.8 \mathrm{mg}$. The child was extubated deep after the airway was cleared of secretions. She was monitored in the Post Anaesthesia Care Unit (PACU) for immediate post-operative complications.

She remained comfortable during recovery and did not show any signs of discomfort over the operation sites. She was discharged to the high dependency unit and prescribed regular Paracetamol and Ibuprofen. Her FLACC pain scale was 0 both after surgery and on Post-Operative Day (POD) 1 with oral Paracetamol. She was discharged well on POD 2.

\section{CONCLUSION}

We believe to be the first to describe a combination of superficial cervical plexus block and PECS 1 block in providing peri-operative analgesia for vagal nerve stimulator implant in paediatric patients. This has shown to be a safe and effective means of providing analgesia; and is a good adjunct to existing simple analgesics such as Paracetamol and NSAIDs.

\section{REFERENCES}

1. Blanco R. The 'pecs block': a novel technique for providing analgesia after breast surgery. Anaesthesia. 2011;66:847-8.

2. Farrukh Munshey et al. Early experience with PECS 1 block for Port-a-Cath insertion or removal in children at a single institution. Journal of Clinical Anesthesia Volume 49,September 2018, Pages 63-64

3. S. Yalamuri, R. Klinger, W. Bullock, et al. Pectoral fascial (PECS) I and II blocks as rescue analgesia in a patient undergoing minimally invasive cardiac surgery. Reg Anesth Pain Med, 42 (2017), pp. 764-766

4. Fujiwara A, Komasawa N, Minami T. Pectoral nerves (PECS) and intercostal nerve block for cardiac resynchronization therapy device implantation. SpringerPlus. 2014;3:409. doi:10.1186/2193-1801-3-409

5. D. Musso et al. A novel combination of peripheral nerve blocks for arthroscopic shoulder surgery. Acta Anaesthesiol Scand. 2017 Oct;61(9):1192-1202. doi: 10.1111/aas.12948. Epub 2017 Aug 4. 